\title{
INIERE-SPACQE
}

\section{A LEGALIZAÇÃO DA BARBÁRIE: a reforma trabalhista e as novas relações de trabalho no Brasil}

\author{
THE BARBARIES LEGALIZATION: labor reform and new labor relations in \\ Brazil
}

\section{LA LEGALIZACIÓN DE LAS BARBARÍAS: reforma laboral y nuevas relaciones laborales en Brasil}

\section{Eder da Silva Cerqueira}

Licenciado e Bacharel em Geografia, Especialista em Administração Pública e Mestre em Desenvolvimento Regional pela Universidade Federal do Tocantins - UFT. edersvp@uft.edu.br / http://orcid.org/0000-0002-6089-0186

Recebido: 22/01/2020; Aceito: 08/01/2021; Publicado: 19/08/2021.

\section{RESUMO}

Este artigo discute as principais mudanças na legislação trabalhista brasileira a partir da entrada em vigor da Lei No13.467/2017, denominada de reforma trabalhista. Considera essa alteração legislativa como resposta da classe hegemônica brasileira às mudanças estruturais no capitalismo globalizado no bojo da denominada reestruturação produtiva [caracterizada pela ascensão do neoliberalismo e pela substituição do fordismo pelo modelo de acumulação flexível]. A metodologia utilizada constituiu-se em pesquisa bibliográfica e consulta a bases de institucionais [PNADcontínua e CAGED]. Conclui que a reforma trabalhista tem se configurado num mecanismo de precarização do trabalho no Brasil, caracterizado pelo erescimento do trabalho intermitente, da informalidade e da subutilização, além de restringir o acesso à justiça do trabalho.

Palavras-chave: Trabalho; Neoliberalismo; Precarização.

\section{ABSTRACT}

This article discusses the main changes in Brazilian labor legislation from the entry into force of Law No. 13,467/2017, called labor reform. It considers this legislative change as a response from the Brazilian ruling class to the structural changes in globalized capitalism within the so-called productive restructuring (characterized by the rise of neoliberalism and the replacement of Fordism by the flexible accumulation model). The methodology utilized consisted of bibliographic research and consultation of institutional bases [PNAD-continuous and CAGED]. It concludes that the labor reform has been configured in a mechanism of work precariousness in Brazil, characterized by the growth of intermittent work, informality and underutilization, in addition to restricting access to labor justice.

Keywords: Work; Neoliberalism; Precariousness.

\section{RESUMEN}

Éste artículo argumenta los principales cambios en la legislación laboral desde la entrada en vigor de Ley $\mathrm{N}^{\circ} 13.467 / 2017$, denominada reforma laboral. Considere este cambio legislativo como respuesta de la clase hegemónica brasileño a los cambios estructurales en el capitalismo globalizado en el bulto de la denominada reestructuración productiva [caracterizada por la ascensión del neoliberalismo y por el reemplazo del fordismo por el modelo de acumulación flexible]. La metodología utilizada constituye en busca bibliográfica y consulta la bases institucionales [PNAD- 
| Eder da Silva Cerqueira |

continua e CAGED]. Concluye que la reforma laboral tiene si configurado en un mecanismo precario del trabajo en Brasil, caracterizado por el crecimiento del trabajo intermitente, de la informalidad y subutilización, además de restringir acceso a la justicia laboral.

Palabras clave: Trabajo; Neoliberalismo; Precariedad.

\section{INTRODUÇÃO}

A partir da segunda metade do século XX as estruturas políticas e econômicas configuradas e implementadas a partir de uma escala planetária se modificaram com uma velocidade e complexidade jamais vistas. É a "mundialização do capital" (CHESNAIS, 1996). Para esse autor, o termo mundialização do capital traduz a capacidade do capital de se transnacionalizar:

A expressão 'mundialização do capital' é que corresponde mais exatamente à substância do termo em inglês 'globalização', que traduz a capacidade estratégica de todo grande grupo oligopolista, voltado para a produção manufatureira ou para as principais atividades e serviços, de adotar, por conta própria, um enfoque e condutas 'globais' (CHESNAIS, 1996, p. 15-16. Grifo do autor).

O termo mundialização do capital expressa um novo momento no desenvolvimento do modo de organização produtiva capitalista, um novo regime de acumulação, um novo patamar do processo de internacionalização do capital, com características próprias e particulares. Esse processo de reorientação nas formas de reprodução das relações de produção capitalistas vai configurar o que o autor denomina de reestruturação produtiva, um sistema de inovações tecnológico-organizacionais no campo da produção social capitalista aplicado à produção e à introdução de novas modalidades de gestão da produção (ALVES, 1998).

O processo de reestruturação produtiva possui vários aspectos. Destacaremos aqui dois deles. O primeiro diz respeito às alterações nas formas de organização produtiva, com a substituição do modelo de produção fordista/taylorista pelo regime de acumulação flexível (toyotismo). O segundo diz respeito à adoção do neoliberalismo como orientação política de gestão pública, com o consequente desmonte do que se convencionou denominar Estado de bem-estar social ou Welfare State. Por esse prisma, o processo de reestruturação produtiva se constitui numa das respostas da burguesia internacional às crises de acumulação do capital, visto que crises econômicas periódicas são vitais para reprodução do modo de produção capitalista, ou seja, são partes constituintes desse modo de organização produtiva, segundo Marx (1984). 
| Eder da Silva Cerqueira |

Embora sejam muito diferentes e não coincidam entre si os períodos durante os quais se inverte capital, as crises, apesar disso, sempre constituem o ponto de partida para grandes e novas inversões de capital. Consequentemente, se encararmos a sociedade em conjunto, a crise gera em maior ou menor grau, uma nova base material para o ciclo seguinte de rotações (MARX, 1984, p. 20).

Crises econômicas, quase sempre, trazem consigo o discurso de que a relação capital/trabalho vigente não responde mais às exigências necessárias para a manutenção “equilibrada” dessa relação contraditória (relação capital/trabalho) e que, portanto, para se alcançar um novo equilíbrio, é necessária a construção de um novo pacto social. Adequações nas estruturas sociais e legais cumprem o papel de tornar a incorporação das mudanças socioeconômicas um processo perceptivelmente menos traumático, que vai se instalando aos poucos, apesar da violência e brutalidade aí imbuídas.

Apesar de manifestarem-se de forma decisiva no aspecto da organização produtiva (substituição do fordismo pelo toyotismo) e no aspecto político (neoliberalismo), as mudanças na forma de reprodução nas relações de produção capitalistas afetaram profundamente outros aspectos da relação capital/trabalho, modificando de forma profunda a vida dos trabalhadores, tanto no aspecto material quando em sua subjetividade, conforme aponta Alves (1999).

A mundialização do capital tende a impulsionar um novo complexo de reestruturação produtiva, uma ofensiva do capital na produção, que busca constituir um novo patamar de acumulação capitalista em escala planetária e que tende a debilitar o mundo do trabalho, promovendo alterações importantes na forma de ser (subjetividade) da classe dos trabalhadores assalariados (ALVES, 1999, p. 79).

A década de 1980 presenciou nos países de capitalismo avançado, profundas transformações no mundo do trabalho, nas suas formas de inserção na estrutura produtiva e nas formas de representação sindical e política. Foram tão intensas as modificações que se pode mesmo afirmar que a "classe-que-vive-do-trabalho" sofreu a mais aguda crise do século, que atingiu não só a sua materialidade, mas teve profundas repercussões na sua subjetividade e no íntimo inter-relacionamento destes níveis, afetando a forma de ser da classe trabalhadora (ALVES, 1999).

No afã de estabelecer uma nova forma de relação capital/trabalho, condizente com as exigências de reprodução do capital, algumas palavras ganham lugar de destaque no discurso hegemônico, dentre elas destaca-se flexibilização. Segundo esse discurso, a rigidez na regulação da relação capital/trabalho, um dos marcos do Welfare State, não é condizente com as formas "modernas" de relação trabalhista e que, portanto, é necessária a adoção de contratos de trabalho flexíveis, que podem ser ajustados de acordo com a necessidade 
| Eder da Silva Cerqueira |

momentânea de reprodução do capital. É nesse cenário que presenciamos a substituição do modelo de produção fordista pelo regime de acumulação flexível.

Sennet (1999), na obra $A$ corrosão do caráter, destaca esse processo de individualização subordinada do trabalhador do "novo capitalismo", em contraposição à estabilidade do modelo burocrático de Weber. No novo capitalismo, diz o autor, o trabalhador é estimulado a uma construção individual e descompromissada de trajetória trabalhista, aparentemente desconectado de qualquer objetivo/destino comum aos demais trabalhadores, mas que concomitantemente, o faz se perder em uma espécie de liberdade para o nada, onde o discurso da flexibilização, potencializado pelas novas tecnologias de comunicação esconde, na verdade, novas ferramentas de controle, mascaradas por uma vaga e suspeita promessa de liberdade (SENNET, 1999).

Dessa forma, o presente artigo tem como objetivo discutir a reforma trabalhista numa perspectiva de resposta da classe hegemônica brasileira às mudanças estruturais no capitalismo globalizado, no bojo da denominada reestruturação produtiva. A metodologia utilizada constituiu-se em pesquisa bibliográfica e consulta a bases de dados secundários institucionais [PNAD-contínua e CAGED]. A importância dessa discussão está em discutir como as formas hegemônicas do capital atuam através dos mecanismos institucionais para potencializar a hegemonia do capital sobre o trabalho, resultando em intensificação e precarização do trabalho via minimização ou até exclusão das formas de proteção legal ao trabalhador.

\section{FLEXIBILIZAÇÃO: o modelo de organização produtiva no capitalismo globalizado}

A origem das grandes transformações na organização produtiva pode ser identificada em meados dos anos 1970, quando as taxas de crescimento econômico se desaceleraram. A produção em série e padronizada estava em crise. Para Harvey (1996), a palavra que melhor representava a incapacidade do fordismo e do keynesianismo ${ }^{1} \mathrm{em}$ conter as contradições capitalistas era a rigidez. A recessão que se abateu sobre a economia mundial pós-1973, agravada pela crise do petróleo, enfraqueceu ainda mais as estratégias fordistas de produção. Nas décadas de 1970 e 1980, novas estratégias de reestruturação

\footnotetext{
${ }^{1}$ Conjunto de ideias que propunha a intervenção estatal na vida econômica, com o objetivo de conduzir a um regime de pleno emprego. Influenciou a renovação das teorias clássicas, que acreditavam que a economia seguiria o caminho do pleno emprego, sendo o desemprego uma situação temporária que desapareceria, graças às forças do mercado.
} 
| Eder da Silva Cerqueira |

econômica passaram a ser adotadas. Inaugura-se um período que afrontava a rigidez do fordismo. A palavra de ordem era flexibilização:

\begin{abstract}
Novos processos de trabalho emergem, onde o cronômetro e a produção em série são substituídos pela flexibilização da produção, por novos padrões de busca de produtividade, por novas formas de adequação da produção à lógica do mercado. Ensaiam-se modalidades de desconcentração industrial, busca-se novos padrões de gestão da força de trabalho, dos quais os "processos de qualidade total” são expressões visíveis não só no mundo japonês, mas em vários pá́ses do capitalismo avançado e do terceiro mundo industrializado (ANTUNES, 2008, p. 26, grifo do autor).
\end{abstract}

Aglietta (1999), também sugere que as formas de acumulação e regulação capitalista de base fordista haviam se esgotado em meados dos anos 1970. Portanto, o capital necessitava recuperar suas taxas de lucratividade que estavam regredindo em função das técnicas tradicionais características do fordismo. Era preciso aumentar a produtividade do trabalho e a remuneração do capital.

Com o esgotamento ${ }^{2}$ do padrão de acumulação fordista emerge um novo modo de gerenciamento do processo de trabalho, o toyotismo. Esse modelo tem como principais características: relacionamento cooperativo entre os gerentes e os trabalhadores, hierarquia administrativa horizontal, controle rígido de qualidade, desintegração vertical da produção. Já não há mais uma rígida separação entre a direção (que pensa) e o operário (que executa). Essas mudanças vão alterar de forma contundente os padrões de organização da vida social. Surge um novo direcionamento na localização e na forma estrutural da produção, da circulação e do consumo, segundo Benko (2002, p. 30):

A passagem para um novo regime de acumulação acompanha-se de mudanças fundamentais multiformes nos modos de produção e de consumo, nas transações e nos mecanismos institucionais de regulação das relações sociais. Elas induzem uma reestruturação espacial da sociedade inteira, redefinição do conteúdo ideológico dos espaços, estabelecimento de uma nova divisão social e espacial do trabalho, criação de novos espaços de produção e consumo (BENKO, 2002, p. 30).

O aumento da força produtiva do trabalho foi a forma encontrada pelo capital para extrair do processo produtivo uma quantidade maior de "mais-valia"”. A transformação do trabalho necessário em trabalho excedente dependia, portanto, de revolucionar as condições técnicas e sociais do processo produtivo, com o intuito de potencializar a força

\footnotetext{
${ }^{2}$ Compartilhamos da ideia de Rosso (2008), para quem, não é por ser ineficiente que o fordismo entra em crise, e sim pelo fato de as formas empregadas para elevar a intensidade do trabalho serem aquém daquelas empregadas pelo toyotismo (ROSSO, 2008, p. 06).

${ }^{3}$ Entendemos aqui por aumento da força produtiva do trabalho, em geral, uma alteração no processo de trabalho, pela qual se reduz o tempo de trabalho socialmente necessário para produzir uma mercadoria, conforme (MARX, 1984).
} 
| Eder da Silva Cerqueira |

produtiva de trabalho e de reduzir seu valor, na medida em que a jornada de trabalho necessária para a reprodução desse valor era abreviada.

Apesar das formas estruturantes de funcionamento do modo de produção capitalista se assemelharem nos diferentes lugares, há também particularidades. Elas se moldam às questões locais, flexibilizam-se de acordo com cada realidade. As mudanças na organização da produção e principalmente nas relações de trabalho são uma espécie de termômetro da sociedade capitalista, constituem-se numa das formas pelas quais podemos captar a dinâmica de funcionamento desse modo de produção, como afirma Fabrini (2004).

\begin{abstract}
As relações sociais de produção e o desenvolvimento das forças produtivas são uma questão central no entendimento da sociedade capitalista, ou seja, há uma correspondência entre o desenvolvimento das forças produtivas e as relações sociais. Entretanto, embora haja esta vinculação entre as relações sociais e as forças produtivas, não há entre elas uma harmonia e uniformidade sincronizada (FABRINI, 2004, p. 06).
\end{abstract}

Assim, para que possamos compreender a natureza do funcionamento do modo de produção capitalista num dado território é preciso que consideremos, além das regras gerais, também as particularidades locais. Em seu livro, O novo (e precário) mundo do trabalho, Alves (1999) traça algumas noções preliminares da introdução desse novo complexo produtivo no Brasil, destacando não só os aspectos objetivos, mas também os aspectos subjetivos, como o desenvolvimento de uma espécie de contracultura aos movimentos de massa, da qual é expressão a crise do sindicalismo.

Com a mundialização do capital, estabeleceu-se um novo complexo de reestruturação produtiva que atingiu a objetividade e a subjetividade do mundo do trabalho. O seu "momento predominante" é o toyotismo, uma lógica de organização da produção de mercadorias com impacto universal e cujo principal objetivo é a constituição de uma subjetividade servil à lógica da valorização (ALVES, 1999, p. 09).

O processo de reestruturação produtiva não se limita a transformações de ordem técnica, tecnológica e/ou organizacional. Ele se complementa a partir da adoção de medidas políticas e socioeconômicas que buscam lhe dar sustentação. Ao conjunto de medidas adotadas na arena política, concomitante à substituição do fordismo pelo modelo de acumulação flexível, convencionou-se chamar ajustes neoliberais ou, simplesmente, neoliberalismo. Dessa forma, para que ocorresse a introdução de mudanças tecnológicas e organizacionais no processo produtivo foi necessária uma série de alterações em outras frentes. Petras (1995) nos chama a atenção para a necessidade de uma análise processual das mudanças na natureza do capitalismo, não nos restringindo às análises dos aspectos puramente técnicos. 
| Eder da Silva Cerqueira |

\begin{abstract}
É preciso salientar que não apenas as determinações tecnológicas contribuíram para impulsionar a nova ofensiva do capital na produção, mas principalmente as determinações políticas, caracterizadas pelo processo político das derrotas históricas da classe trabalhadora, ocorridas nas conjunturas dos anos 70 e 80 nos principais países capitalistas (PETRAS, 1995, p. 35).
\end{abstract}

Para possibilitar a implementação de alterações tecnológicas e organizacionais na esfera produtiva, o capital atuou concomitantemente em outras frentes, como a política e a econômica, produzindo justificativas ideológicas para tanto. Uma dessas frentes foi a alteração nas formas de atuação política dos estados nacionais, que, diferentemente do protagonismo de que gozavam à época do Welfare State, tiveram seu papel redefinido.

\title{
NEOLIBERALISMO: a face política do processo de reestruturação produtiva
}

O processo de reorganização produtiva teve também forte atuação na arena política, reorientando a atuação dos estados nacionais. O estado, como regulador das relações sociais, teve papel fundamental nesse processo, passando de um estado intervencionista - Welfare State - para um modelo de intervenção mínima, sobretudo nas questões econômicas.

Segundo Faleiros (2000), o Welfare State resultou de pactos sociais entre classes de interesses contrários, o que assegurou a implantação de novos direitos de cidadania e distribuição de renda. O modelo nasce da proposta do economista britânico John Maynard Keynes como alternativa para superar a crise de 1929. As propostas de Keynes incluíam o incentivo à produção e ao emprego, visando acelerar o crescimento econômico. Essa proposta política tinha como característica principal a forte atuação do Estado por intermédio de políticas públicas sociais que garantisse necessidades básicas dos trabalhadores como saúde, educação e segurança.

O objetivo principal era que o trabalhador gastasse o menor percentual possível de seu salário com necessidades básicas, direcionando seus recursos à aquisição de bens de consumo. Dessa forma potencializar-se-ia o consumo, gerando um círculo virtuoso de crescimento, com benefícios para os capitalistas e para a classe trabalhadora. Caberia ao Estado a regulamentação da economia, oferecendo subsídios aos capitalistas e assegurando certo padrão de consumo aos trabalhadores, por intermédio dos salários e de políticas sociais. A atenção do Estado para com a proteção social justificava-se, visto que:

O Estado buscava canalizar o fundo público, tanto para o financiamento do capital, quanto para a reprodução da força de trabalho, movido pela lógica de que, para impulsionar a produção, há que ampliar mercados e preservar um 
| Eder da Silva Cerqueira |

certo poder aquisitivo da população, capaz de viabilizar o consumo de mercadorias e a dinamização da economia (IANAMOTO, 1998, p. 30).

O Welfare State assumiu versões diversas, conforme os objetivos de cada país e as configurações políticas de cada território. $\mathrm{Na}$ América Latina, seu principal papel foi impulsionar a economia por meio do estímulo ao consumo. Nos países europeus atuou numa perspectiva mais política, com características sociais-democratas, visando ampliar os direitos de cidadania e a distribuição de renda.

Os defensores de um Estado neoliberal bradam por uma "mínima" intervenção estatal na economia. No entanto, defendem uma atuação estatal forte em setores ditos “estratégicos", sobretudo, naqueles que necessitam da aplicação de uma grande quantidade de capital. Antunes (2008) cita algumas das principais características que marcaram a implantação do neoliberalismo na Inglaterra, na era Thatcher, e nos EUA, na era Reagan, apontando os princípios fundamentais desse modelo de gestão estatal:

\footnotetext{
Menos industrializante e mais voltado para os serviços, menos orientado para a produção e mais financeiro, menos coletivista e mais individualista, mais desregulamentado e menos contratualista, mais flexível e menos "rígido", mais fundamentado no laissez-faire, no monetarismo e totalmente contrário ao estatismo nacionalista (ANTUNES, 2008, p. 61).
}

Apesar do discurso de Estado mínimo, com a redução do papel estatal em arenas decisórias, não foi o que se presenciou na prática. O Estado não foi excluído da arena decisória, ao contrário, passa a cumprir, por excelência, o papel de financiador e justificador das ações do capital, colocando-se a serviço das grandes corporações multinacionais. Portanto, o Estado-Nação não deixa de ser um ponto nodal da atividade política. Além de principal agente ativo na esfera política, este cumpre ainda o papel de regulador da força de trabalho, papel esse que nenhum outro poderia fazer em seu lugar, visto que a gestão da força de trabalho ocorre física, cultural e ideologicamente no âmbito doméstico.

O peso político-ideológico da queda do comunismo teve importância decisiva para implantação do neoliberalismo. A ideologia capitalista disseminava-se como única possibilidade para superação da crise econômica:

A derrota comunista e o avanço das ideias e políticas dos novos liberais para o Leste Europeu e mesmo, já hoje mais recentemente, para os países da Ásia, tem dado ao pensamento neoliberal, condições sem precedentes de que jamais o liberalismo gozou, de uma ideologia que consegue ser quase universalmente hegemônica. (...) é indiscutível que o liberalismo nunca teve, nunca alcançou tamanha difusão ou hegemonia no plano mundial como neste final de milênio (FIORI, 1997, p. 215). 
| Eder da Silva Cerqueira |

Ao analisarmos a implantação do neoliberalismo não podemos deixar de tomar, como indicador de análise, os fatores históricos, econômicos, sociais e políticos de cada país. Naqueles países com acentuada desigualdade social e com problemas estruturais como desemprego, fome, indigência e analfabetismo, portanto, muito mais suscetíveis à imposição de agenda neoliberal, o processo é bastante diferenciado. Ademais devemos considerar, ainda, que em muitos países não se consolidou um Estado de Bem-Estar Social pleno.

Enquanto no início dos anos de 1970 os países centrais atravessavam um momento de crise econômica e de críticas ao Welfare State, no Brasil se processavam movimentações populares por eleições diretas. Foi um período de lutas pela redemocratização do país, somente conquistada no final da década de 1980. Esses movimentos representavam uma denúncia política e social da realidade brasileira que culminaram na elaboração da Carta Constitucional de 1988, a qual estabelecia a universalização dos direitos, a liberdade do indivíduo e a seguridade social.

Por aqui, o modelo neoliberal se pautou em reformas que priorizavam a lógica do ajuste fiscal, o que resultou em perdas de direitos e conquistas históricas dos trabalhadores, constituindo-se no que Behring (2003) denomina de "contrarreforma neoliberal". Segundo essa autora, estava em curso no Brasil nos anos 1990 uma contrarreforma do Estado, caracterizada pela perda de direitos dos trabalhadores.

A partir do Governo Collor até o final do Governo Temer, o projeto neoliberal permaneceu intocável como condutor principal da agenda política e econômica brasileira. Apesar de algumas diferenças em determinadas áreas, do ponto de vista estrutural os diferentes governos que se revezaram no poder, após a redemocratização, permaneceram inarredáveis dos princípios emanados pelos organismos internacionais, como Banco Mundial e Fundo Monetário Internacional, conforme veremos com mais detalhes no tópico a seguir.

Após a explanação teórica acerca das profundas mudanças na relação capital/trabalho, com destaque para mudança do modelo de organização produtiva fordista para o regime de acumulação flexível e para a emergência do neoliberalismo como orientação de gestão pública, trataremos doravante de como essas mudanças se refletiram no Brasil até desembocar na entrada em vigor da Lei $N^{\circ} 13.467 / 2017$, da denominada reforma trabalhista.

LEI $N^{\circ}$ 13.467/2017: a reforma trabalhista e as novas relações de trabalho no Brasil 
Após a entrada em vigor da Constituição de 1988 iniciou-se no Brasil um intenso processo de abertura econômica e desregulamentação visando à integração comercial. Acordos bilaterais e multilaterais foram viabilizados proporcionando a quebra de fronteiras legais para a reestruturação econômica industrial interna, constituindo avanços para os investimentos, vendas e lucros. Sob a batuta de organismos multilaterais (FMI e Banco Mundial), diversos países foram compelidos a adotar um novo aparato jurídico articulado com o livre mercado, favorecendo a abertura para o capital internacional. Dentre os mandamentos da cartilha neoliberal, una tríade se destacava: ajuste fiscal, flexibilização de direitos sociais e desregulamentação do mercado. O cumprimento dos mandamentos fundamentais da cartilha era a condição imprescindível para a integração comercial, de acordo com Scoleso (2017).

\footnotetext{
A mundialização do capital sob o signo do neoliberalismo deu origem a uma dinâmica de integração da economia mundial que pressionou muitos países na década de 1990 a assumir as mesmas determinações como condição de se integrar ao novo mercado mundial (SCOLESO, 2017, p. 201).
}

Esse movimento em direção aos mandamentos do neoliberalismo na gestão do governo nacional inicia-se logo após a entrada em vigor da Constituição de 1988, mantendo uma trajetória unificada, do ponto de vista estrutural, nos diferentes governos pós redemocratização. Com o objetivo de conter a crise econômica e ajustar a economia, o governo Collor formula o Plano Brasil Novo, que consistia numa série de dispositivos legais para compensar a indústria brasileira e auxiliá-la no processo de reestruturação. Sob a batuta da Ministra Zélia Cardoso de Mello, entram em vigor as Diretrizes para a política industrial e para o Comércio Exterior.

Diferente do processo de substituição de importações, a nova política industrial e de comércio exterior buscava a transformação do mercado interno por intermédio das "formas de mercado" a fim de induzir as alterações necessárias para modernização do parque industrial e, consequentemente, promover o aperfeiçoamento das formas de organização da produção e da gestão da força de trabalho (SCOLESO, 2017, grifos da autora). Em relação ao mundo do trabalho, o período é caracterizado pela diminuição da quantidade de trabalhadores, inserção de políticas de treinamento e no enxugamento de cargos e salários, bem como das estruturas hierárquicas.

No mesmo movimento de abertura comercial e desregulamentação da economia pós-redemocratização, tem início, no governo Itamar, os Programas de Desenvolvimento Tecnológico e Industrial (PDTI) e o de Desenvolvimento Tecnológico e Agropecuário (PDTA) que articulavam o desenvolvimento endógeno de inovações tecnológicas, com o 
| Eder da Silva Cerqueira |

objetivo de gerações de novos produtos e/ou processos e o aprimoramento de suas características mediante a execução de programas de pesquisa ou desenvolvimento próprios.

O governo FHC foi marcado pela aprovação de mudanças constitucionais de ordem econômica, como a quebra dos monopólios estatais, igualdade de tratamento entre empresas nacionais e estrangeiras, e a desregulamentação de atividades econômicas consideradas estratégicas. Essas mudanças vão resultar numa modificação estrutural do cenário de emprego, profundamente marcado pela abertura comercial e consequente reestruturação produtiva que engloba inserção de avanços tecnológicos e a introdução de novas formas de produção e organização do trabalho.

Segundo Scoleso (2017), as mudanças implementadas pelos governos FHC atingiram de forma profunda a classe trabalhadora, afetando diretamente os níveis de empregabilidade e de qualidade dos postos de trabalho.

\footnotetext{
A desestatização de uma parcela significativa de empresas também contribuiu para um saneamento dos postos de trabalho e consequente aumento das taxas de desemprego, de ocupações precárias e do aumento de trabalhadores sem carteira assinada (SCOLESO, 2017, p. 204).
}

Nos governos Lula e Dilma, as diretrizes da política econômica permaneceram praticamente as mesmas, do ponto de vista estrutural, apesar do destaque para algumas políticas de ordem social. O processo de abertura comercial e de desregulamentação financeira continuou, bem como algumas políticas características da cartilha neoliberal, como privatizações, políticas de ajuste fiscal com vistas à garantia do regular pagamento da dívida e redução de direitos sociais (inclusos direitos trabalhistas).

Cabe destacar a reforma da previdência implementada no primeiro ano do primeiro governo Lula, movimento considerado como uma das primeiras ações de adesão do governo aos ditames da cartilha neoliberal, sinalizando assim a continuidade, em linhas gerais, do projeto de contrarreforma da previdência iniciado por FHC, na década de 1990. A reforma penalizou principalmente os servidores públicos ao extinguir a aposentadoria integral, embutir previdência complementar e taxar os inativos. Após essa primeira reforma, se sucederam várias ações dos governos Lula e Dilma no sentido de aprofundar o projeto neoliberal brasileiro. Não resta dúvidas que houve uma continuidade das políticas neoliberais fundamentais, mantendo-se a perspectiva da estabilidade monetária, juros altos, superávit fiscal, manutenção do sistema tributário regressivo, independência do Banco Central, enfim, todo o arcabouço de medidas que caracterizaram o projeto neoliberal tupiniquim. 
| Eder da Silva Cerqueira |

No recente governo Temer, iniciado após o impedimento da Presidente Dilma Rousseff, a trajetória política e econômica do Brasil permaneceu inalterada. Cabe destacar que durante o governo Temer houve um avanço mais rápido (considerando o conturbado processo de transição e o tempo em que permaneceu no poder) das políticas de austeridade fiscal e de desregulamentação dos direitos sociais, com a aprovação da chamada Proposta de Emenda Constitucional (PEC 95), que limitou os investimentos do Estado nas áreas de proteção social por 20 anos e o início das discussões da reforma da previdência (aprovada no governo Bolsonaro), além da entrada em vigor da Reforma Trabalhista, objeto de discussão desse trabalho.

Portanto, a trajetória política e econômica do Brasil, desde a redemocratização, tem se caracterizado pela adoção dos mandamentos emanados pelos organismos multilaterais, materializando-se na construção de instrumentos jurídicos que permitissem ao Estado e ao capital nacional e estrangeiro reconfigurar suas ações para se integrar aos novos ditames internacionais e integrar esse novo ciclo de acumulação capitalista mundializada e financeirizada. Entre os condicionantes ditados pelos organismos multilaterais para a entrada do Brasil no circuito internacional de reprodução do capital sob o signo do neoliberalismo destacava-se a flexibilização dos direitos sociais, portanto, dos direitos trabalhistas, o que significou uma profunda alteração na morfologia do trabalho.

\footnotetext{
Os resultados desse processo para a classe trabalhadora podem ser vislumbrados pela desregulamentação do mercado e pela adoção de um processo de flexibilização das leis trabalhistas que, ao tempo, conduziu a classe trabalhadora a um intenso processo de precarização (SCOLESO, 2017, p. 195).
}

É nesse contexto de alterações nas formas de regulamentação da relação capital x trabalho, em tempos de neoliberalismo e de ação do modelo de acumulação flexível, que se insere a entrada em vigor no Brasil da Lei No 13.467/2017. Publicada no Diário Oficial da União em 14/07/2017. A referida Lei, denominada genericamente de reforma trabalhista, alterou de forma contunde o Decreto-Lei $\mathrm{N}^{\circ}$ 5.452, de 01 de Maio de 1943, popularmente conhecido como Consolidação das Leis do Trabalho (CLT), até então, o principal marco regulatório da relação capital/trabalho no Brasil. Antes da entrada em vigor da CLT, o Brasil não dispunha de uma normativa uniforme sobre as relações de trabalho, de forma que a CLT é considerada uma conquista da classe trabalhadora, pois a partir de sua vigência garantiu-se condições mínimas de trabalho regulamentadas nacionalmente.

Antes da entrada em vigor da CLT, as legislações vigentes tratavam da regulamentação de algumas categorias profissionais específicas ou ainda diziam respeito a determinadas questões de direito processual do trabalho. Também não havia uma 
| Eder da Silva Cerqueira |

regulamentação completa sobre o rito de processos trabalhistas. A CLT permitiu ainda que os trabalhadores pudessem reivindicar melhores condições de trabalho e o cumprimento das leis que regulamentavam questões como jornada de trabalho, remuneração, férias e etc. Pela lei, os funcionários também não poderiam ser presos e nem punidos por fazer greves e manifestações.

É a partir desta época que os sindicatos são regulamentados e começam a atuar de forma legal, reunindo as reivindicações dos trabalhadores e cobrando das empresas a garantia de direitos. Antes da CLT, também não havia a obrigação de um salário-mínimo a ser pago todo mês aos trabalhadores. A criação do Ministério e da Justiça do Trabalho também são conquistas importantes advindas da CLT. Com a entrada em vigor da reforma trabalhista, grande parte desses direitos passaram a ser suprimidos ou flexibilizados, visto que em nossa visão a reforma constitui uma resposta da classe dominante nacional às exigências do capital financeiro na busca pela expansão de riquezas em escala global.

Numa arena de concorrência acirrada e elevada competição entre as empresas, a agenda da flexibilidade dos direitos trabalhistas ganhou protagonismo afetando duramente as condições de vida da classe trabalhadora, resultando em intensificação e precarização do trabalho, conforme dizeres de Lúcio (2019, p. 02).

\footnotetext{
A finalidade dessa reforma é reduzir o custo do trabalho; criar a máxima flexibilidade para a alocação da mão de obra por meio da introdução de contratos vulneráveis e ajustes de jornada; facilitar as demissões e minimizar seus custos; impedir a criação de passivos trabalhistas; restringir as negociações e incentivar a realização de acordos por empresas com representações laborais controladas, em detrimento de contratos e convenções com abrangência ampla, inviabilizando a ação dos sindicatos.
}

A reforma trabalhista trouxe diversas alterações nos mais diversos aspectos das relações trabalhistas. Umas das principais mudanças trazidas pela reforma trabalhista é a regulamentação dos contratos de trabalho intermitente. De acordo com o texto da reforma, o contrato intermitente é aquele em que o trabalhador só será pago pelo período trabalhado. $\mathrm{O}$ trabalhador será chamado quando houver serviço, com antecedência mínima de 03 (três) dias, e só vai receber (salário e direitos) correspondentes às horas em que trabalhar. Se não houver serviço, não recebe. Essa alteração contraria o estabelecido no artigo $4^{\circ}$ da CLT, segundo a qual "Considera-se como de serviço efetivo o período em que o empregado esteja à disposição do empregador, aguardando ou executando ordens, salvo disposição especial expressamente consignada” (BRASIL, 2019).

A partir da entrada em vigor da reforma trabalhista o trabalho intermitente foi a modalidade de contrato de trabalho que mais cresceu no país. A partir de novembro de 
| Eder da Silva Cerqueira |

2017 - entrada em vigor da reforma trabalhista - os contratos de trabalho intermitente registraram saldo positivo em todos os meses, diferente do que ocorreu no total de vagas de trabalho formais. De acordo com dados do Cadastro Nacional de Empregados e Desempregados (CAGED), de novembro de 2017 a julho de 2019 foram criados 606.390 postos de trabalho formais no país. Desse total 101,6 mil (15,4\%) foram de vagas de trabalho intermitente.

Do total de vagas de trabalho intermitente mais de $70 \%$ foram abertas no setor de comércio e serviços. Enquanto o setor de serviços abriu 47.661, o comércio registrou a abertura de 25.386 vagas de trabalho. Nesse mesmo período, os setores de construção civil e de indústria de transformação foram responsáveis por $26 \%$ das vagas de trabalho intermitentes criadas. Enquanto a construção civil abriu 14.648 vagas, a indústria de transformação criou 12.182 vagas. Outras atividades como Agricultura, Serviços Industriais de Utilidade Pública e setor extrativo mineral, somadas, geraram 3\% das vagas de trabalho intermitente, conforme pode ser consultado no Gráfico 1.

Gráfico 1 - Criação de Vagas de Trabalho Intermitente por setor de atividade - Série Nov. de 2017 a Julho de 2019

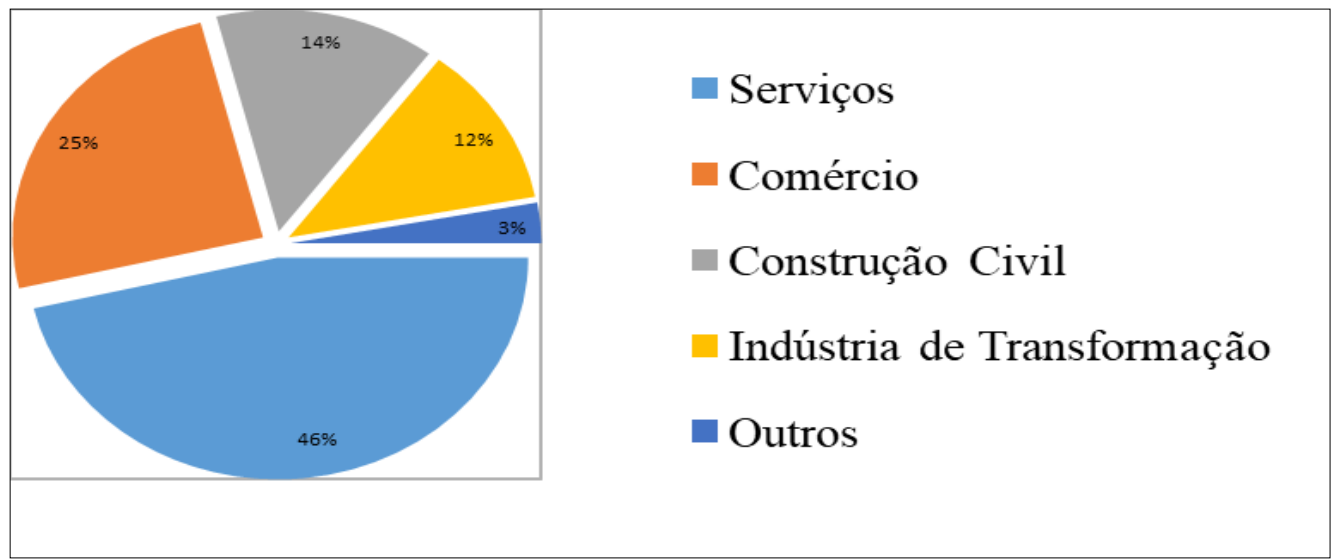

Fonte: CAGED - Ministério da Economia, 2019.

O aumento de vagas de trabalho intermitente em detrimento da criação das vagas de trabalho em tempo integral representa a subsunção real do trabalho ao capital, outorgando aos empregadores o poder discricionário sobre os trabalhadores, na medida em que os mantêm em uma situação de extrema vulnerabilidade e controle sobre sua jornada de trabalho. A adoção dessa modalidade de trabalho objetiva, sobretudo, reduzir o número de trabalhadores centrais e empregar cada vez mais uma força de trabalho, com alta rotatividade.

A reforma trabalhista trouxe ainda diversas mudanças no que diz respeito ao acesso do trabalhador à justiça do trabalho. A partir da entrada em vigor da nova lei o trabalhador 
| Eder da Silva Cerqueira |

terá que arcar com custas processuais em casos de ausência em audiência judicial (salvo se comprovado no prazo de 15 dias a sua ausência por motivo legalmente justificável), terá ainda que arcar com os honorários advocatícios da parte vencedora em casos de perda de ações, além de ser obrigatório especificar os valores pedidos nas ações.

Outra novidade é que se o juiz entender que o empregado agiu de má-fé ele poderá ser multado e terá ainda de indenizar a empresa. Há, ainda, a fixação do valor de indenizações em ações por danos morais, que agora se limitam a 50 vezes o valor do último salário contratual do trabalhador. Em casos em que a justiça decidir que o trabalhador agiu de má-fé, é possível também a cobrança dos honorários advocatícios e indenização para a parte contrária.

Essas mudanças tiveram como consequência uma profunda restrição no acesso à justiça do trabalho. De acordo com dados do Tribunal Superior do Trabalho (TST), o número de ações trabalhistas ajuizadas entre janeiro e setembro de 2018 foi 36\% menor do que o volume registrado no mesmo período do ano anterior. Enquanto que de janeiro a dezembro de 2017 as varas do trabalho receberam 2.013.241 de reclamações trabalhistas, nesse mesmo período de 2018 houve recebimento de 1.287.208, conforme podemos visualizar nos dados do Gráfico 2.

Chama atenção a queda número de reclamações ajuizadas em dezembro de 2017 na comparação com novembro do mesmo ano, período de transição até a entrada em vigor da reforma trabalhista. Antes da vigência da referida lei, foram ajuizadas 289.704 ações na justiça do Trabalho. Um mês após a entrada em vigor da reforma, em dezembro de 2017, esse número caiu para 84.229 mil ações, uma queda de mais de $700 \%$, conforme destaca os valores do gráfico abaixo.

Gráfico 2 - Número mensal de ações na justiça do Trabalho - Série de Janeiro de 2017 a Dezembro de 2018

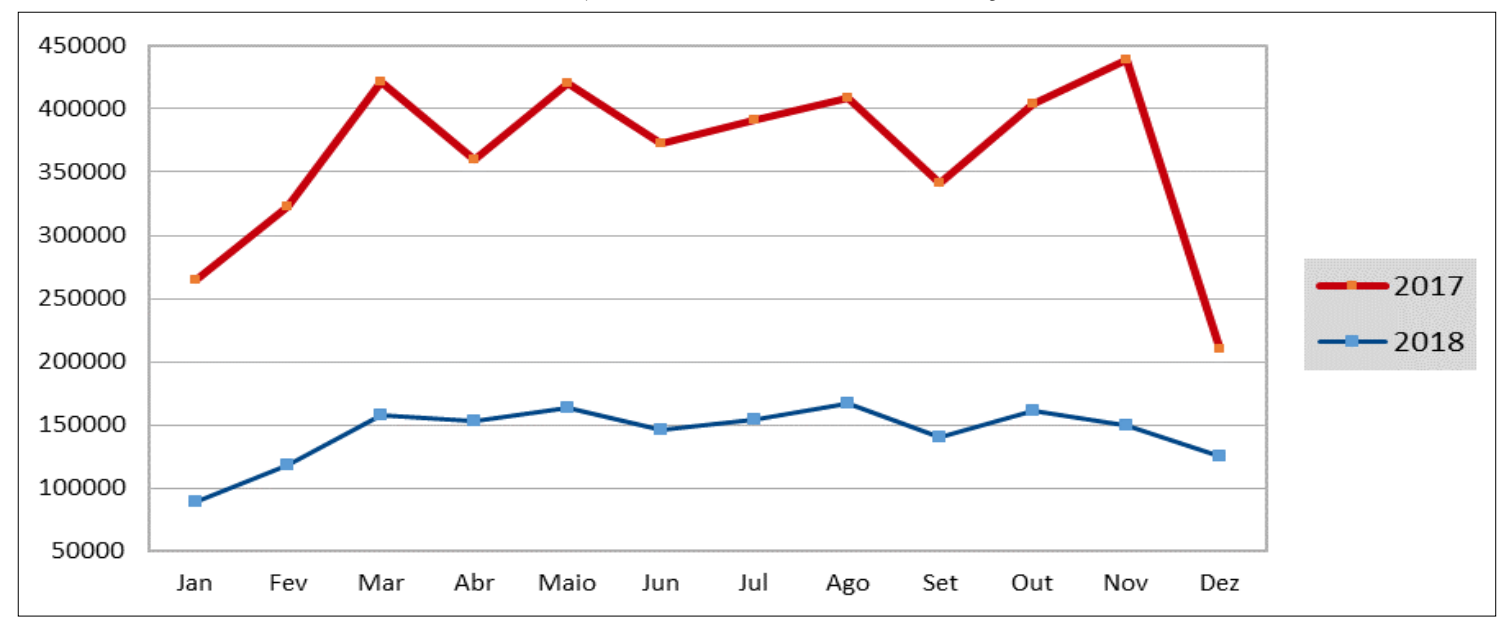

Fonte: Tribunal Superior do Trabalho (TST, 2019). 
| Eder da Silva Cerqueira |

A queda no número de ações ajuizadas na justiça no trabalho é reflexo das restrições no acesso à justiça do trabalho imposta pela reforma, conforme asseverado por Gonçalves (2019, n.p):

Se a reforma tivesse trazido pacificação social a ponto de reduzir a demanda, ótimo. Mas não foi isso que aconteceu. $\mathrm{O}$ desrespeito aos direitos continua a existir. O que aconteceu é que as pessoas procuram menos a Justiça do Trabalho pelo valor dos custos que têm que pagar em caso de perda de ação, o que não existia anteriormente.

A presidente da Associação Nacional dos Magistrados da Justiça do Trabalho (ANAMATRA), Noemia Porto, também argumenta nesse sentido. Para a magistrada, as regras trazidas pela reforma trabalhista têm significado restrição no acesso dos trabalhadores à justiça do trabalho. Segundo ela,

\begin{abstract}
a reforma trabalhista, de fato, representou negativa de acesso ao Poder Judiciário trabalhista. Há um ambiente de medo, de insegurança, em razão do fato de que antes o processo judicial trabalhista era acessível e universal e agora se estabelece esse patamar de custas processuais e honorários (PORTO, 2019, n.p).
\end{abstract}

Outra consequência nefasta para a classe trabalhadora decorrente da reforma trabalhista é a informalidade. Segundo dados da última Pesquisa Nacional por Amostra de Domicílios Contínua (PNAD-Contínua), há no Brasil 38,6 milhões de trabalhadores atuando no mercado de trabalho informal. Esse contingente representa $41 \%$ da força de trabalho total no país (estimada em 105 milhões de trabalhadores). De cada 10 empregos criados atualmente na economia brasileira, somente 01 (um) é de carteira assinada. Os outros postos de trabalho estão todos muito próximos da informalidade, são autônomos, trabalhadores por conta própria, trabalhadores domésticos e/ou familiares, conforme pode ser conferido no Gráfico 3:

Gráfico 3 - Distribuição de trabalhadores informais por situação

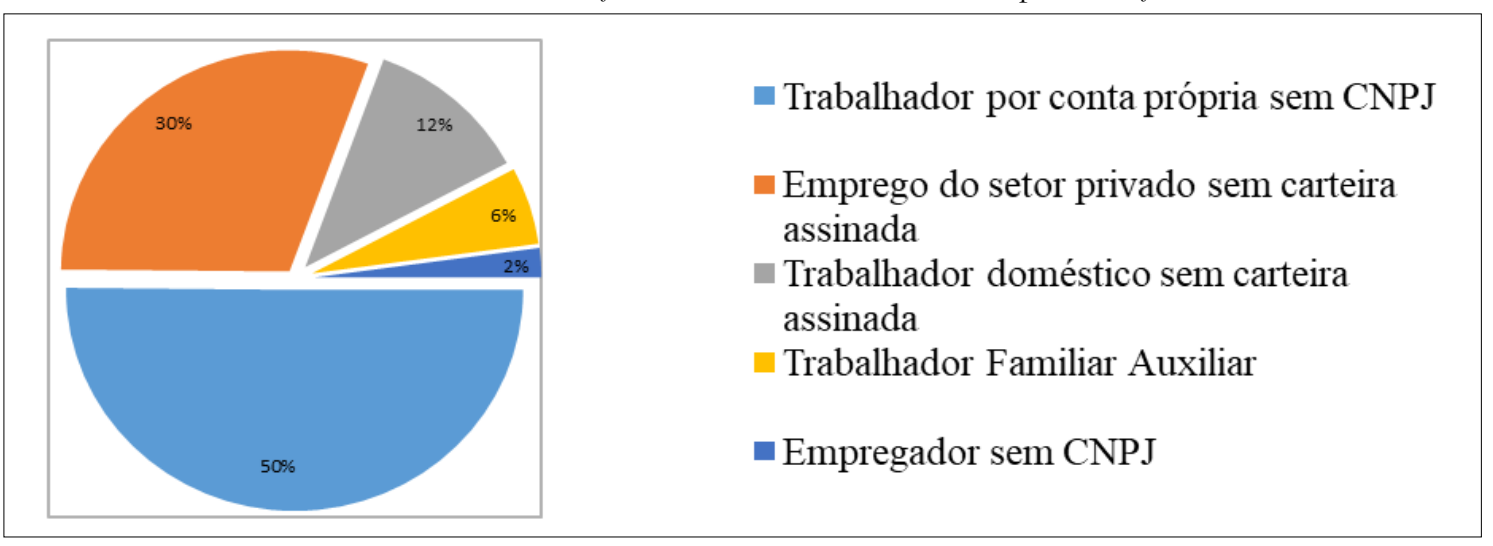

Fonte: PNAD - Contínua (IBGE, 2019). 
| Eder da Silva Cerqueira |

Dos mais de 38 milhões de brasileiros na informalidade, 19,42\% trabalham por conta própria sem Cadastro Nacional de Pessoa Jurídica (CNPJ), enquanto que 11,79\% são empregados no setor privado sem carteira de trabalho assinada. Nesse montante estão ainda os trabalhadores domésticos sem carteira assinada (4,5\%), os que se ocupam de trabalho familiar auxiliar $(2,19 \%)$ e ainda aqueles que se encontram na situação de empregador sem CNPJ (0,83\%).

O crescimento da informalidade no cenário de desemprego em alta é dos sintomas mais claros de precarização do mercado de trabalho no Brasil. Em termos de comparação, segundo dados do Instituto Brasileiro de Geografia e Estatística (IBGE), o rendimento médio do trabalhador do mercado de trabalho informal é cerca de 35\% menor do que o trabalhador com carteira de trabalho assinada. Enquanto o trabalhador com carteira assinada recebe cerca $R \$ 2.169$ mensais, o empregado por conta própria possui renda média mensal de $\mathrm{R} \$$ 1.427. "É uma situação no conjunto muito adversa, com uma penalização extrema para os trabalhadores, uma insegurança muito alta e uma falta de perspectiva para ter acesso a um posto de trabalho de qualidade" (LÚCIO, 2019, n.p).

Para a economista e pesquisadora do Departamento Intersindical de Estatística e Estudos Socioeconômicos (DIEESE), Adriana Marcolino, o crescimento do trabalho informal maquia os impactos da crise econômica no país. Com as novas regras da reforma trabalhista, assistimos a um constante processo de precarização no mercado de trabalho no Brasil. A reforma trabalhista primeiro deixou o trabalhador mais vulnerável, porque o empregador ganhou mais poder nas relações de trabalho, e por outro lado criou-se uma série de contratos de trabalho que maquiam situações precárias, como o trabalho intermitente, em que se contrata uma pessoa em uma situação praticamente "de bico". (MARCOLINO, 2019, grifo da autora).

Outra constatação da PNAD-Contínua é o crescimento da subutilização. Segundo a pesquisa, no $1^{\circ}$ trimestre de 2019, o Brasil contava com um contingente de 27,775 milhões de trabalhadores subutilizados. Desse total, 12.565 milhões eram de trabalhadores desempregados, o que representa $45,3 \%$ do total de subutilizados. $O$ contingente de trabalhadores subutilizados era composto ainda por 7.233 milhões de trabalhadores subocupados ${ }^{4}$, o que representa 26,1\%. Compõe ainda o universo de trabalhadores subutilizados a força de trabalho em potencial, que é composta por trabalhadores desalentados $^{5}$ mais os trabalhadores desocupados 7.957 (28,7\%), ou seja, trabalhadores que

\footnotetext{
${ }^{4}$ Trabalhadores que laboram menos de 40 horas semanais.

5 Trabalhadores que desistiram de procurar emprego.
} 
| Eder da Silva Cerqueira |

possuíam potencial para o trabalho, mas não se encontravam ocupados, conforme pode ser observado no gráfico abaixo:

Gráfico 4 - Distribuição de Trabalhadores subutilizados no Brasil no $3^{\circ}$ trimestre de 2019

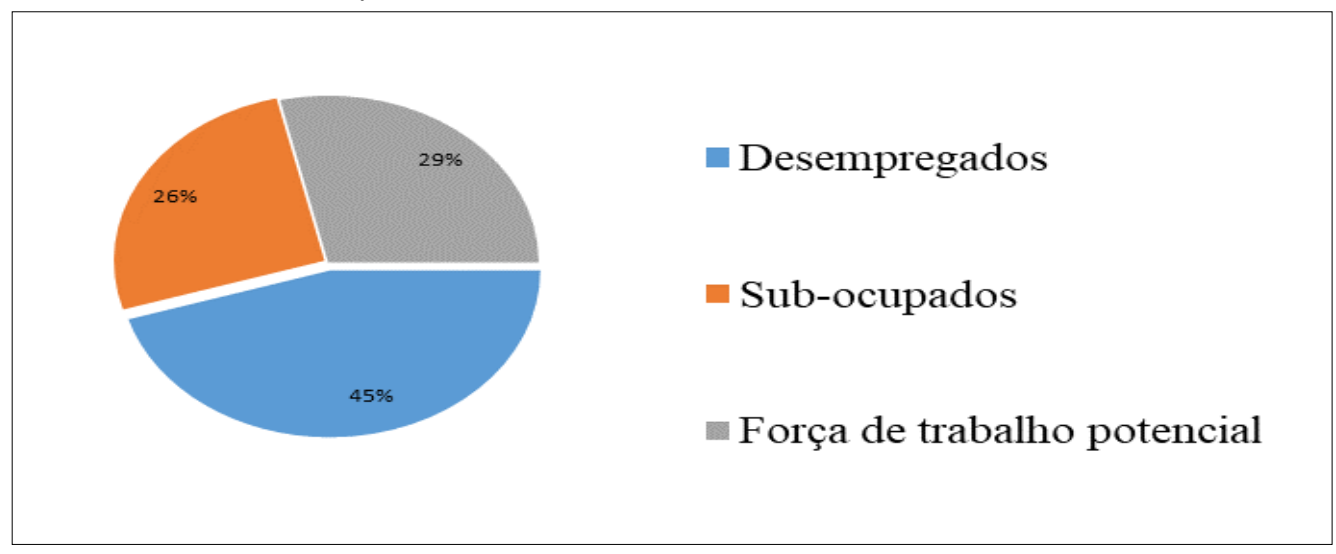

Fonte: PNAD-Contínua (IBGE, 2019).

Diante dos dados apresentados resta evidenciar como a Reforma Trabalhista tem resultado em perda de direitos, além de um processo de intensificação e precarização do trabalho, como podemos observar nos gráficos acima. As antigas formas de trabalho típicas do período fordista, caracterizadas pela linearidade e previsibilidade na carreira, vêm sendo substituídas de maneira acelerada por formas de trabalho intermitentes, com a força de trabalho ocupada de acordo com as demandas pontuais e sazonais. Essa mudança tem contribuído para um aumento constante da informalidade, resultando num dado impressionante: praticamente metade de todos os trabalhadores ocupados na economia brasileira atua na informalidade, o que inclui trabalhadores sem carteira, trabalhadores domésticos sem carteira, empregador sem CNPJ, trabalhador por conta própria sem CNPJ e trabalhadores auxiliar familiar.

Segundo Scherer (2019), as pessoas ocupadas em postos de trabalho informais tendem a viver com maiores restrições pessoais, por conta de problemas relacionados à pobreza, além de uma maior insegurança nas questões de saúde do trabalhador. Para além das questões de ordem social, há ainda uma questão de ordem econômica relacionada à questão da produtividade, visto que os postos de trabalhos informais

\footnotetext{
são ocupações de baixa produtividade, que exigem pouca qualificação, que incorporam uma tecnologia muito básica, essas ocupações informais normalmente não preparam a força de trabalho para evoluir, para absorver melhorias tecnológicas e, também, obviamente, que isso tem repercussão não só do ponto de vista econômico, mas também social (SCHERER, 2019, n.p).
}

Além do crescimento do trabalho intermitente, outra consequência da reforma trabalhista foi o crescimento da subutilização do trabalho, constituída pelos trabalhadores 
| Eder da Silva Cerqueira |

desempregados e subocupados, ou seja, trabalhadores que possuem força de trabalho potencial, mas não a utilizam por falta de oportunidade de trabalho, mesmo aqueles trabalhadores que possuem uma ocupação, trabalham menos horas semanais do que gostariam de trabalhar. Esse percentual de trabalhadores subutilizados é composto ainda pelos desalentados, aqueles trabalhadores desempregados que desistiram de procurar trabalho por falta de perspectiva de encontrar uma ocupação.

Outra mudança estrutural advinda da reforma trabalhista, talvez a mais importante, foi a substituição do legislado pelo "negociado". A partir da entrada em vigor da reforma, existe a possibilidade da prevalência do que for pactuado em âmbito de Acordo Coletivo de Trabalho (Sindicato de Trabalhadores e empresa) e Convenção Coletiva de Trabalho (entre sindicato dos trabalhadores e sindicato patronal), sobre o legislado. Ou seja, todos os direitos sociais que foram conquistados ao longo do tempo pelas diversas insurreições e movimentos operários podem ser desconsiderados a partir de uma "negociação" entre o patrão e o empregado, praticamente um cheque em branco para o empregador impor suas condições de contratação, sem a atuação da justiça do trabalho.

Além da prevalência do negociado sobre o legislado, a reforma trabalhista também trouxe a possibilidade do trabalhador arcar com os honorários advocatícios sucumbenciais, além do pagamento de honorários periciais e de custas processuais, caso o trabalhador perca uma ação por reclamação trabalhista. Essa previsão provocou uma queda vertiginosa no número de ações trabalhistas após a entrada em vigor da reforma, caracterizando-se em mais um atentado aos consagrados direitos trabalhistas e um ataque fervoroso à dignidade da pessoa humana. Essas são apenas algumas das graves consequências negativas para a classe trabalhadora pós-reforma trabalhista. Diante de um cenário de economia em crise, ajustes fiscais e ataque às conquistas sociais, o cenário para a classe que vive do trabalho não parece ser muito animador.

\section{CONSIDERAÇÕES FINAIS}

Ao prefaciar o livro Mais trabalho! A intensificação do labor na sociedade contemporânea, de autoria de Sadi Dal Rosso, Antonio David Cattani revela como o desenvolvimento tecnológico e o aperfeiçoamento das técnicas de produção de bens e materiais ocorridas nas últimas décadas, apesar de proporcionar o experimento de experiências de vida inéditas, tem resultado num completo desastre social e ambiental. Temos acesso a diversas formas de socialização - mediadas por aparatos tecnológicos de ponta - inéditas, ao mesmo tempo 
| Eder da Silva Cerqueira |

em que convivemos com experiências reprováveis de condições de trabalho e de vida, além do agravamento dos problemas advindos da nossa relação com o meio ambiente.

Jamais na história houve tamanha criação material: bens e serviços abundantes e de melhor qualidade, inovações que proporcionaram mais conforto e saúde, possibilidade de fruição de novas dimensões de vida, disponibilidade de aparatos tecnológicos que facilitam os deslocamentos e as comunicações dos indivíduos. Porém, o preço a pagar tem se revelado absurdamente alto. A lógica inexorável do princípio da acumulação ilimitada e da concentração do capital tem levado à destruição da natureza e ao crescimento das desigualdades socioeconômicas de modo indigno.

A intensificação do neoliberalismo e o aprofundamento do modelo de acumulação flexível tem resultado em intensificação e precarização do trabalho. No Brasil, esse processo pode ser observado com nitidez na explosão da informalidade, no aumento do trabalho intermitente, na criação de restrições no acesso à justiça do trabalho e no crescimento da subutilização. Um novo estágio de exploração, focado no enaltecimento do trabalho autônomo e com pouca cobertura de direitos sociais.

\section{REFERÊNCIAS}

AGLIETTA, Michel. "Regulación y crisis del capitalismo". Tradução de Marcos Paulo da Silva. 6. ed. México: Siglo Veintiuno Editores, 1999.

ALVES, Giovanni. Reestruturação produtiva e crise no sindicalismo no Brasil. Tese de Doutorado. IFCH/Unicamp. 1998.

ALVES, Giovanni. Trabalho e mundialização do capital: A nova degradação do trabalho na era da globalização. $2^{a}$ Edição. Práxis: Londrina: 1999.

ANTUNES, Ricardo. Os sentidos do trabalho: ensaio sobre a afirmação e a negação do trabalho. São Paulo (SP), Boitempo Editorial, 1999.

ANTUNES, Ricardo. Adeus ao trabalho: ensaios sobre a metamorfose e centralidade do trabalho. 13. ed. rev. ampl. São Paulo: Cortez, 2008.

BEHRING, Elaine Rossetti. Brasil em contra-reforma - desestruturação do estado e perda de direitos. São Paulo: Cortez, 2003.

BENKO, Georges. Economia, Espaço e Globalização na aurora do século XXI. Tradução de Antonio de Pádua Danesi. 3. ed. São Paulo: Hucitec/Annablume, 2002.

BRASIL. Consolidação das Leis do Trabalho. Decreto-Lei $n^{\circ}$ 5.442, de 01 de maio de $1943 . \quad$ Disponível em: $<$ http://www.planalto.gov.br/ccivil 03/DecretoLei/Del5452compilado.htm>. Acesso em: 03 out. 2019. 
CAGED. Cadastro Nacional de Empregados e Desempregados. Base de Dados online. Disponível em: < https://caged.gov.br/index.html/>. Acesso em: 06 out. 2019.

CATTANI, David Antonio. In: DAL ROSSO, Sadi. Mais trabalho! A intensificação do labor na sociedade contemporâneo. São Paulo: Boitempo, 2008.

CHESNAIS, François. A mundialização do capital. São Paulo: Xamã, 1996.

DAL ROSSO, Sadi. Mais trabalho! A intensificação do labor na sociedade contemporâneo. São Paulo: Boitempo, 2008.

FABRINI, João Edmilson. Contradição como parâmetro de compreensão da existência camponesa. Geografia (Londrina), v. 13, n. 2, p. 116-138, 2004. Disponível em: $<$ http://www.uel.br/revistas/uel/index.php/geografia/article/view/6776>. Acesso em: 06 out. 2019.

FALEIROS, Vicente de P. A política social do Estado Capitalista: as funções da Previdência e Assistência social. 8. ed. São Paulo: Cortez, 2000.

FIORI, José Luís. Globalização, hegemonia e império. In: TAVARES, Maria da Conceição; FIORI, José Luís (Org.). Poder e dinheiro. Uma economia política da globalização. Petrópolis: Vozes, 1997. p. 87-147.

GONÇALVES, Antônio Fabrício. Reforma trabalhista reduz processo e muda a vida de advogados: "fonte secou". Disponível em: $<$ https://doutoradevogado.jusbrasil.com.br/noticias/729947958/reforma-trabalhistareduz-processos-e-muda-vida-de-advogados-fonte-secou>. Acesso em: 07 out. 2019.

IBGE. Instituto Brasileiro de Geografia e Estatística. Pesquisa Nacional por Amostra de Domicílios. $2019 . \quad$ Disponível em: $<$ https://agenciadenoticias.ibge.gov.br/media/com mediaibge/arquivos/d12e28f89183a3 25025c7073a02ba535.pdf >. Acesso em: 02 out. 2019.

HARVEY, David. Condição Pós-Moderna. 6. ed. São Paulo: Edições Loyola, 1996. p. 117-184.

IAMAMOTO, Marilda Vilela. O Serviço Social na contemporaneidade: trabalho e formação profissional. 2. ed. São Paulo: Ed. Cortez, 1998.

LÚCIO, Clemente Ganz. IBGE aponta que 38,6 milhões de brasileiros trabalham na informalidade. Nível bate recorde. Rede Brasil Atual. 2019. Disponível em: $<$ https://www.redebrasilatual.com.br/trabalho/2019/09/ibge-sem-carteira-assinadainformalidade/>. Acesso em: 28 set. 2019.

MARCOLINO, Adriana. Cresce o número de trabalhos informais após novo modelo de contratação. Sindicato dos bancários e financiários de São Paulo, Osasco e Região. 2018. Disponível em: <https://spbancarios.com.br/02/2018/cresce-o-numero-detrabalhos informais-apos-novo-modelo-de-contratacao >. Acesso em: 01 out. 2019.

MARX, Karl. O Capital. São Paulo: Abril Cultural, 1984. (Coleção Os Economistas, volume I, tomo 2). 
| Eder da Silva Cerqueira |

PETRAS, James. Ensaios Contra a Ordem. Editora Scritta, Campinas: Editora Scritta, 1995.

PORTO, Noemia. Reforma trabalhista reduz processos e muda vida de advogados: 'Fonte secou'. Granadeiro Guimarães Advogados. Disponível em: <http://www.granadeiro.adv.br/clipping/2019/07/08/reforma-trabalhista-reduzprocessos-e-muda-vida-de-advogados-fonte-secou >. Acesso em: 01 set. 2019.

SENNET, Richard. A corrosão do caráter: as consequências pessoais do trabalho no novo capitalismo. Rio de Janeiro: Record, 1999.

SCHERER, Clóvis. Aumento da informalidade não é surpresa. Brasil de Fato, 2020. Disponível em: $\quad<$ https://www.brasildefato.com.br/2020/01/31/aumento-dainformalidade-nao-e-surpresa-afirma-economista-do-dieese $>$. Acesso em: 13 jan. 2021.

SCOLESO, Fabiana. Os movimentos sociais na era da mundialização do capital e da precarização do mundo do trabalho: neoliberalismo e transnacionalização. Revista de História Comparada, Rio de Janeiro, v. 11, n. 01, p. 1925-225, 2017.

TRABALHO, Tribunal Superior do. Primeiro ano da Reforma Trabalhista: efeitos. Disponível em: $<$ http://www.tst.jus.br/notícias//asset publisher/89Dk/content/id/24724445>. Acesso em: 02 out. 2019.

\section{Como citar:}

\section{ABNT}

CERQUEIRA, E. S. A legalização da barbárie: a reforma trabalhista e as novas relações de trabalho no Brasil. InterEspaço: Revista de Geografia e Interdisciplinaridade, v. 7, e202119, 2021. Disponível em: <http://dx.doi.org/10.18764/2446-6549.e202119>. Acesso em: 15 ago. 2021.

\section{APA}

Cerqueira, E. S. A legalização da barbárie: a reforma trabalhista e as novas relações de trabalho no Brasil. InterEspaço: Revista de Geografia e Interdisciplinaridade, v. 7, e202119. Recuperado em 15 agosto, 2021, de http://dx.doi.org/10.18764/2446-6549.e202119

\section{@creative}

This is an open access article under the CC BY Creative Commons 4.0 license.

Copyright (C) 2021, Universidade Federal do Maranhão.

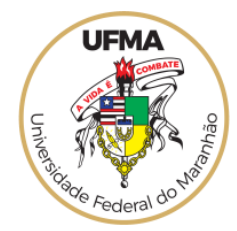

